\title{
Toward Effective International Technology Assessments
}

\author{
KAN CHEN and LECH ZACHER
}

ABSTRACT

A cross-national understanding of technology policy decision processes and basic premises underlying technology assessment must be established before an effective technology assessment methodology can be developed to conduct substantive technology assessments on an international scale.

\section{Introduction}

Technology assessments are policy-oriented systematic studies of the social impacts and the social management of science and technology. With its increasing power, scale and complexity, technology and its impacts respect no national boundary. Earth-oriented space satellites launched by one country can gather information about all countries. Carbon dioxide and fluorocarbon released from one geographical region can have longterm effects on the global climate. Nuclear technologies developed by a nation bloc may be improved and applied by another nation bloc. There are natural resources, such as those in the Antarctic, which should be developed and utilized to the benefit of the entire world only through some appropriate international collaboration, using technologies which would not cause undue damage to the environment.

Thus, the use of earth-orbiting satellites; international environmental issues; global search for new sources of energy; exploitation of new resources in the Antarctic, in the oceans, or in the outer space of planets; international transportation problems; the danger of manipulating people and societies with the help of science and technology (medical, biological, chemical, electronic and communication technologies); military technologies, etc., are important subjects not only for philosophical and ethical considerations, but also for policy-oriented international technology assessments. One should stress above all that the liquidation of the specter of nuclear holocaust and the achievement of worldwide disarmament are not just political issues for, in the course of their practical resolutions, the broad and long-range consequences of the powerful military technologies and must therefore be carefully assessed.

In addition to the avoidance of global disasters due to the misuse of science and technology, international technology assessments are also necessary in some constructive activities. A case in point is technology transfer across nations, which has been mostly commercial in character, and occasionally in the form of technical assistance via bilateral

PROFESSOR KAN CHEN is with the Department of Electrical and Computer Engineering at the University of Michigan, Ann Arbor, Michigan, USA.

PROFESSOR LECH ZACHER works at the Polish Academy of Sciences, Institute of Philosophy and Sociology and in the Academy's Research and Prognostic Committee 'Poland 2000", Warsaw, Poland. 
or multilateral arrangements. However, technology transfer, especially to the Third World countries, has been traditionally consıaered mainly on the basis of technical and economic feasibility. This has resulted in certain undesirable cultural side effects of technology transfer, such as technological overdependence on foreign countries, uprooting of the rural unemployed and their migration to the urban ghettos, mismatch between the demand for skilled factory workers and the supply of theoretical scientists, and the intellectual brain drain $[1,2]$. It is time for international technology assessments that will include the careful analysis of the value systems, societal goals, and politico-cultural possibilities in both the technology transmitting and the technology receiving countries, so that appropriate technologies will be developed and adopted by the Third World countries.

It has been long recognized by practically all countries in the world, that national science and technology policies cannot be made without international considerations. Moreover, it is now clear that cooperation and some coordination provide better results. Frequent international meetings of science ministers of various countries, both in the East and in the West, have taken place in the past decade [3]. Technology assessment, intended to provide useful information for technology policy making, has acknowledged at its formative stage the importance of its international aspect. The name of International Society for Technology Assessment (ISTA), which is probably the only existing professional society in this field, testifies to this acknowledgment. To date, ISTA has held two international congresses and a number of conferences in various countries, facilitating the exchange of ideas and experiences among the users and doers of technology assessment from many OECD, CMEA, and Third World countries [4]. While these exchanges have enabled the sharing and comparison of technology assessment methodologies and experiences in various individual countries, no full-fledged technology assessment project has been attempted, nor will it be likely in the near future, to involve an international team of professionals working on a substantive problem of international or global significance, with the intention of providing serious inputs to the technology policy makers in the countries involved. This is especially true for projects that would involve Eastern and Western countries, inspite of the need for international technology assessments in such areas as satellites, nuclear power, and the $\Lambda$ ntarctic, as mentioned previously, which will require international collaborations especially between the East and the West.

\section{The Contextual Dimension of Technology Assessment}

It has been said that science is an international language. This is true to the extent that all physical and natural scientists, irrespective of their nationalities, by and large use the same basic methods for scientific inquiries. Although technology assessment is still a relatively new field, the basic methods used by technology assessment practitioners from different countries appear to be rather similar, inasmuch as they generally apply systems analysis approaches to provide interdisciplinary linkages for engineering, economics, cybernetics, sociology, law, and other relevant branches of knowledge [5]. Thus, at first glance, the internationalization of technology assessment appears relatively easy. A more careful examination of the ultimate purpose of technology assessment, however, leads to a less sanguine conclusion. This is because of the policy orientation, which puts technology assessment in a larger and more complex social context than pure science.

First of all, a commonality of methods does not necessarily imply a commonality of methodologies, which are particular combinations of the component methods for doing technology assessment in such a way that the results are useful to the policy makers. Each set of selected methods constitutes a methodology [6]. The appropriate choice of a 


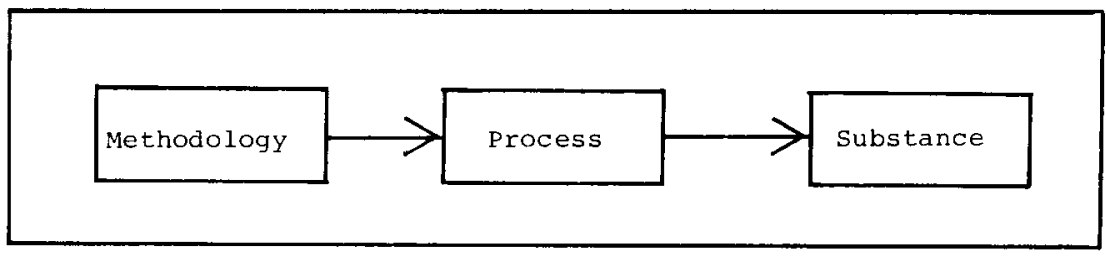

Fig. 1. Effective technology assessments are predicted on the compatibility among methodology, processes and substance imbedded in the context of a set of basic premises.

methodology depends on the policy making process through which a substantive problem is solved (or through which a substantive issue is resolved). An effective technology assessment is accomplished only if the methodology, the process, and the substance are all mutually compatible within the context of a set of basic premises. Figure 1 shows conceptually this contextual imbedding for effective technology assessment. Of course, the total imbedding shown in the diagram represents only an ideal situation. The basic premises of technology assessment include the cultural image of technology in society, and the expected role of technology assessment in policy making. The substantive problem is also imbedded in the basic premises, as in Fig. 1, since the definition of any substantive problem and its relative significance are culturally dependent.

A corollary of the idea in Fig. 1 is that technology assessment will not be effective if the methodology, the process, and the substance are not imbedded in the same basic premises. An example is the nonutilization of technology assessment when the doers and the users, living in different cultures or subcultures even in the same country, do not share the same premises underlying technology assessment [7]. On the other hand, Fig. 1 should be interpreted with flexibility. Technology assessments can still have some effectiveness even if the methodology, the process, and the substance are not totally imbedded in the same premises. Moreover, hasic premises may be changed and shared through communication and interaction among people in different cultures. And this is usually the real situation.

The concept in Fig. I suggests that international technology assessment is more difficult than technology assessment conducted by a single nation because international technology assessment, to be effective, must deal with multifarious policy making processes and divergent premises. The degree of divergence increases as the cultural distance among the nations involved in the international technology assessment increases. The efficacy of technology assessment, already plagued by the epistemological distance among various disciplines [8] in ordinary cases, is further weakened by the cultural distance among different nationals when it is internationalized.

Of course, searching for an effective international technology assessment methodology does not necessarily mean the acceptance of a single or a completely unified approach. Starting from very simple basic assumptions, we can expand and then decompose our approach, considering various parameters which will modify and affect the primary general approach. Let us consider some examples of such parameters. Table 1 shows the implications of considering the time-horizon parameter. The dynamics of most technological processes are such that effective international policy actions in the short run will be oriented toward stopping some harmful technologies (by international agreements of ban treaty type), that those in the medium run will be oriented toward substituting current technologies in one country by borrowing and adapting technologies from another coun- 
TABLE 1

\begin{tabular}{|c|c|c|c|c|}
\hline $\begin{array}{l}\text { Orientation of } \\
\text { TA results }\end{array}$ & Short & $\begin{array}{l}\text { Time-horizon } \\
\text { Medium }\end{array}$ & Long & $\begin{array}{l}\text { Type of international cooperation } \\
\text { in implementing TA results }\end{array}$ \\
\hline $\begin{array}{l}\text { Stopping } \\
\text { technology }\end{array}$ & $x$ & & & International agreements \\
\hline $\begin{array}{l}\text { Substituting } \\
\text { technology }\end{array}$ & & $\mathrm{x}$ & $\mathrm{x}$ & Technology transfer \\
\hline $\begin{array}{l}\text { Developing } \\
\text { technology }\end{array}$ & & & $\mathrm{x}$ & $\begin{array}{l}\text { Cooperation in long-term } \\
\text { R\&U projects }\end{array}$ \\
\hline
\end{tabular}

try, and that those in the long run will be oriented toward developing new technologies, fulfilling the internationally accepted goals, on the basis of scientific and technological cooperation (via long-term R\&D projects, involving a number of nationals leading to "programmed" desirable technologies).

Another important parameter will be the socio-political and institutional system of the countries involved in international technology assessments. There is a feedback path especially in the long run, which links the use of science and technology in a society to its societal goals determined by the socio-political system. In international technology assessments involving countries with very different systems (e.g., market economies and centrally planned economies) extra efforts must be made to prepare a set of common criteria for assessment (e.g., on the basis of the United Nations' agreements) and to set up a set of common (or at least mutually understood and accepted) decision and implementation mechanisms. The socio-political and institutional parameters are very important because they determine not only the goals but to a greater extent the mechanisms of their realization. In other words, a general approach would have severe limitations without this specific consideration.

Still another important parameter which ought to be considered in the international technology assessments is the level of economic, technological, and political (methods and styles of decision-making) developments in the participating countries. Generally speaking, the stage of development determines, at least in the short and medium run, goals and tasks as well as the mechanisms of their implementation. Idealistic goals of technological development will not be very meaningful in the case of poverty and scarcity of resources, since a narrow range of economic alternatives would in turn severely limit technological choices. On the other hand, in the case of affluence and availability of resources, a broad range of economic and social alternatives are possible, and so will be the technological means for goal realization. International technology assessinents can be effective only if the involved parties are fully aware of these differentiating parameters.

Although no pair of nations have identical premises and processes of technology assessment, there are elements of similarities as well as differences. At the outset of this paper are given examples of substantive problems of common concern to many nations. If effective international technology assessment is to be accomplished, the elements of similarities and differences in the premises and processes of technology assessment in the collaborating countries must be identified before a meaningful and effective methodology 


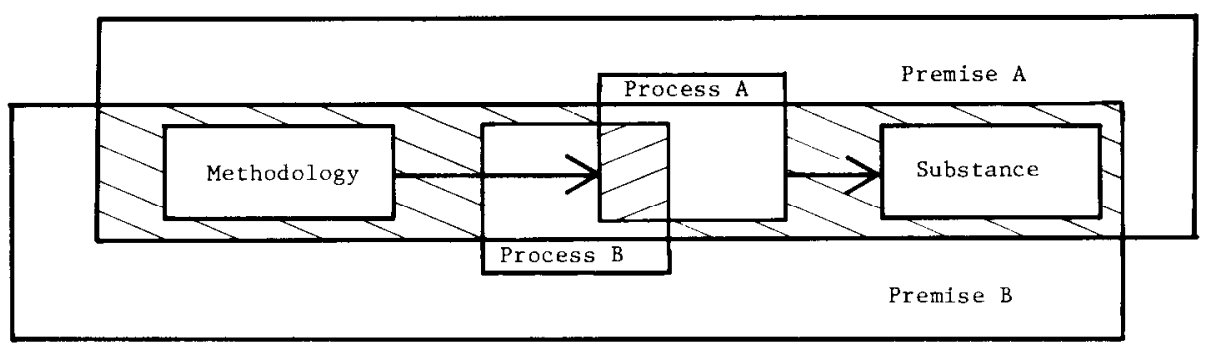

Fig. 2. Common methodology can be developed for international technology assessment of common substantive problems by emphasizing the elements of similarities in premises and processes.

can be developed. Figure 2 shows conceptually how effective international technology assessment can be accomplished by emphasizing similarities as well as understanding the differences between countries. As suggested by the diagram, effective methodologies could be developed on the basis of the elements of similarities in premises and processes even though there may be many elements of differences.

\section{Example of Cross-National Comparison}

To illustrate what we mean by similarities and differences in technology assessment premises and processes, we will make a preliminary cross-national comparison between typical OECD countries and typical CMEA countries. ${ }^{1}$ We do this comparison with the bclicf that any significant problems, such as those mentioned previously, can be solved only if there are effective international technology assessments involving both OECD and CMEA countries. We do this as a first step toward a more comprehensive cross-national comparison, as we recognize that there are important differences between OECD countries [9] and between CMEA countries, and that Third World countries must also be involved in international technology assessments.

A central element of similarity in technology assessment premises between OECD and CMEA countries is that technologies that have broad social implications should be brought under social control. The philosophical assumptions underlying technology assessments are recognized by researchers in OECD countries as in contrast with the traditional laissez faire attitude toward technological development [10]. In CMEA countries, technology assessment has been viewed as a basis for the effective management of science and technology, again in contrast with the traditional laissez faire attitude towards science and the traditional belief that science is unmanageable [5]. In OECD countries, technology assessment has been associated with the historical trend of increasing intrusion of public concerns in the practice of the engineering profession [11]. Even the immense success of science and technology, because of their demand on limited resources, has led to the political problem of how to guide and manage technological progress for the well-being of society [12]. The social management of technology. which has long been a practice in centrally planned economies $[13,14]$, is becoming an increasingly accepted concept in OECD countries [15].

Inspite of the above similarities, there are significant differences in technology assessment premises between the OECD and CMEA countries. In the former, technology

1 The comparison has been based on a cursory review of the literature and a brief working relationship between the authors. An in-depth analysis is in order for any serious international technology assessment. 
assessment, in identifying the consequences of technological developments which would be valued differently by different social groups, has become a vehicle to reflect diverse social values in political debates on technology policy. In the CMEA countries, technology assessment has become a tool for efficient technology management within the framework of a central plan which reflects certain social values $[5,16,17]$. This difference probably manifests a deeper dichotomy between historical determinism (in a stochastic rather than mechanical interpretation) [18] and the image of man as a free being capable of choosing his destiny among a wide range of alternative futures [19].

The policy making processes within which technology assessment must operate have similarities between the OECD and the CMEA countries. For example, large-scale technological developments, i.e., space exploration, nuclear power, etc., are largely under the control and regulation of national government agencies. The two-communities theories - that technology assessment doers and users live and operate in separate worlds with different and often conflicting values, different reward systems, and different languages [7] - probably have equal validity in explaining and predicting the difficulty in effective use of technology assessment in real policy making in both OECD and CMEA countries. Finally, the absence of a powerful international governing body which has the authority to legislate and enforce international laws makes international technology assessment equally difficult in this respect for all countries.

The major difference in policy making processes with respect to technology assessment lies in the fact that most technological initiatives and decision in the OECD countries lie within the private sector, whereas this is not the case in the CMEA countries. Internationally, the multinational corporations play a significant though controversial role in technology transfer and resource flow to and from OECD countries [20], but only a minimum role in CMEA countries. As a result of the difference in the basic premises

TABLE 2

Elements of Similarities and Differences

in Technology Assessment Premises and

Processes between OECD and CMEA Countries

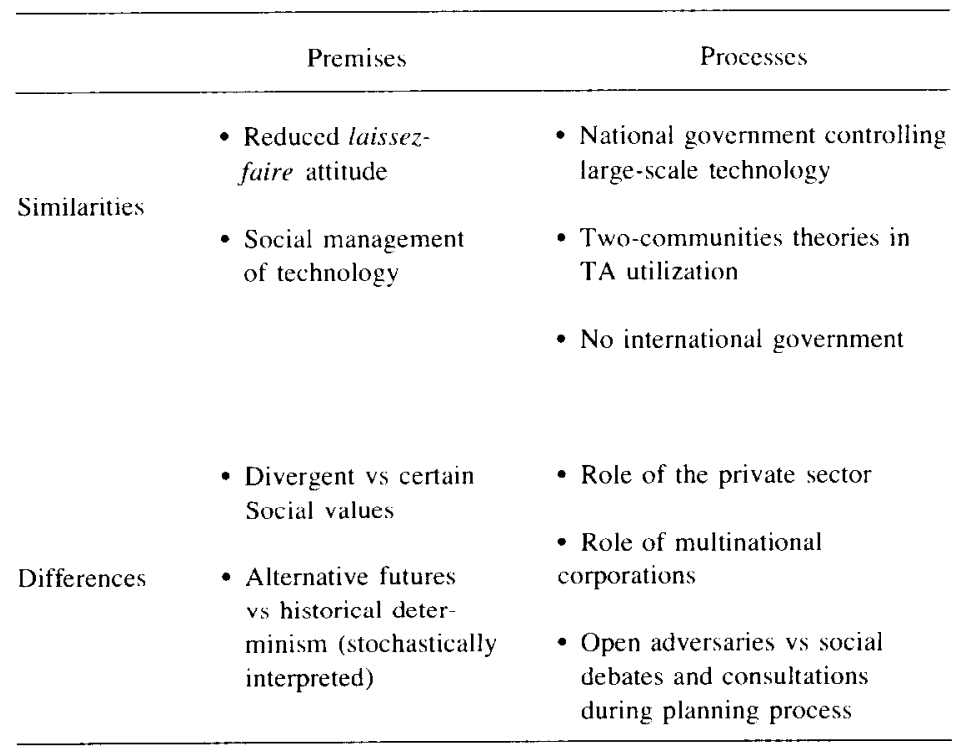


discussed previously, value conflicts in technology assessment are frequently visible in OECD countries through open adversarial processes [21], whereas similar cases are usually handled through central planning and social debates and consultations in CMEA countries [22].

The above similarities and differences are tabulated in Table 2. We maintain that while we should emphasize the similarities in the development of effective international technology assessment methodologies, we should also be aware of, and be sensitive to, the differences in order to avoid unnecessary snarls. Moreover, the differences could also provide an opportunity for mutual learning. For example, the experience of OECD countries in dealing with diverse goals and values in technology assessment would be helpful when there are conflicting goals and values between countries participating in international technology assessments. On the other hand, the experience of CMEA countries in normative technology assessment can be exploited once sufficient agreement on some specific goals and criteria for an international technology assessment is reached.

\section{An Agenda for Future Work}

The above example is no more than a beginning of a cross-national understanding of technology assessment premises and processes, an understanding which we believe is a prerequisite for effective international technology assessments. What steps could be taken toward the development of useful methodologies and the establishment of effective institutions for international technology assessments? We would like to propose an agenda for possible future work as follows:

1. Establish an in-depth cross-national understanding of technology assessment premises and processes for two or several countries or groups of countries.

2. Develop a tentative common methodology for international technology assessment involving these same countries, agreeing especially on the treatment of diverse values, uncertainties, and project integration.

3. Select a pertinent substantive area for international technology assessment involving these countries.

4. Conduct a pilot technology assessment project and learn from the experience.

5. Conduct a full-fledged technology assessment project using, if necessary, a modified and improved common methodology.

6. Conduct international technology assessments in other substantive areas involving the same countries.

7. Repeat, or conduct in parallel, the above steps for a different set of countries.

8. Generalize and modify international technology assessments involving the union of sets of countries.

9. Update step 8 on a continuing basis.

10. Institutionalize international technology assessments [23].

The above agenda represents, of course, one of many possible approaches. The agenda can be put into motion through bilateral collaboration between two countries, through multinational research programs (such as those sponsored by the International Institute of Applied Systems Analysis [24], the Organization for Economic Cooperation and Development, the Council for Mutual Economic Assistance, etc.), or through the United Nations agencies (Office for Science and Technology [1,2], the United Nations University, etc. [25]). A loose coalition and liaison among some or all of the above programs and agencies is probably the most desirable and feasible way to proceed. 
The agenda suggested above shows how international technology assessments could gain depth in a sequence of steps. It is not necessary that all the ten steps be taken before breadth is attempted. In fact, we would suggest that a balanced approach be taken to increase both depth and breadth simultaneously, though gradually. A broad international technology assessment program would include: (1) cooperation in the field of information and administration of technological development (intergovernmental level, international agencies' level, etc.); (2) joint international technology assessment projects in substantive areas (e.g., arms control, space exploration, protection of the global environment, searching for new resources of energy, developing appropriate technologies, etc.); (3) joint R\&D programs and projects concerning technology assessment methodologies; (4) agreements limiting $R \& D$, production, and distribution of harmful or dangerous technologies (e.g., in the fields of biology, medicine, chemistry, etc.); (5) creation of an international or global early-warning system for monitoring and predicting the possible negative effects of science and technology; (6) effective dissemination of substantive technology assessment results for any government or other entities; and (7) popularization of the technology assessment concept and methods by various forms of education (international universities, summer schools, conferences, publications, mass media, etc.).

Special attention should be given to the problem of technology assessment application within Third World countries involving nationals of these countries. Choice of a "technological path" for the developing countries is crucial and should not be limited only to technological and economic aspects. It would be desirable to compare and reanalyze the "intermediate" or "appropriate technology" concept $[26,27]$ together with the concept of technology assessment. Limits and opportunities of "late-comers" situation" should be assessed, using multidimensional criteria (e.g., internal self-reliance possibilities and barriers, versus external aid possibilities and hazards). International (e.g., African, Asian, or South American) and world (the United Nations) organizations responsible for scientific and technological assistance to the developing countries should assess the cultural and social impacts of this assistance in order to promote technological developments which are genuinely suitable to their specific needs and conditions. Truly effective international technology assessments involving the Third World would lead to a reshaping of not only economic [28], but also scientific and technological world order.

\section{Conclusions}

We believe that an in-depth cross-national understanding of technology assessment premises and processes is a prerequisite for international technology assessment, which will involve the nationals of two or more countries and provide serious inputs to the technology policy making pertinent to some substantive problems shared by these countries. Appropriate and effective common methodologies can then be developed for international technology assessments involving these countries without a complete agreement on premises and processes. Eventually, new and effective methodologies and institutions for international technology assessments can emerge after sufficient learning from the actual experience through international collaborative efforts.

\section{Notes and References}

1. United Nations, Office for Science \& Technology, Report of the Expert Group on Technology Assessment, New York, report 76-40534, (June 23-27, 1975).

2. Kennerley, John A. and Ovcharenko, Valeriy, Technology Assessment and the Development Process, Second International Congress on Technology Assessment, Ann Arbor, Michigan, October 1976.

3. For example. five meetings of Ministers of Science have been held under the auspices of the Organization 
for Economic Cooperation and Development (OECD) of the 24 industrialized, market-economy nations of Western Europe, the United States, Canada, Japan, Australia, and New Zealand. These meetings have been prepared by a standing committee concerned with scientific and technological policy issues which reports to the OECD Council made up of the permanent Heads of National Delegations to the OECD. Similar meetings were organized in the $1960^{\circ}$ s by UNESCO. Within the CMEA (Council for Mutual Economic Assistance) is an active special commission for the scientific and technological cooperation.

4. The First International Congress on Technolog: Assessment was held at the Hague, the Netherlands, in May 1973. The Second International Congress on Technology Assessment was held at Ann Arbor. Michigan. in October 1976.

5. Dobrov, Gennady M., Technology Assessment in the USSR or the Science of Science: A Basis for the Effective Management of Scientific Activity, Technology Assessment 1 (3) 191-200, (Gordon \& Breach Science Publishers. L.td.. London). (1973).

6. Arnstein. Sherry R. and Christakis, Alexander N., Perspectives on Technology Assessment, Science and Technology Publishers, Jerusalem, 1975, p. 73.

7. Caplan, Nathan, Morrison, Andrea and Stanbough, Russell J., The Use of Social Science Knowledge in Policy Decision at the National Level. Institute for Social Research, The University of Michigan, 1975.

8. Rossini, Frederick A., How Can We Put It Together? A First Model of Technology Assessment Integration, Georgia Institute of Technology, 1976.

9. Vlachos, Evan C., Transnational Interest in Technology Assessment, paper presented at the Second International Congress on Technology Assessment, Ann Arbor, Michigan, October 1976.

10. Chen, Kan and Zissis, George J., Philosophical and Methodological Approaches to Technology Assessment, J. Internat. Soc. Technol. Assessment 1 (1), 17-28 (1975).

11. Kranzberg, Melvin, Designing for Engineering Futures, paper presented at the Second International Congress on Technology Assessment. Ann Arbor, Michigan, October, 1976.

12. King, Alexander, Report on the First Theme, Parliamentary Democracy in the Scientific-Technological Age, Council of Europe, Third Parliamentary and Scientific Conference, Lausanne April 11-14, 1972, p. 3; quoted in Francois Hetman, Society and the Assessment of Technology, 1973, p. 45 (OECD, Paris).

13. Dobrov, Gennady M., TA \& TF for the Management of R\&D in the USSR, paper presented at the Second International Congress on Technology Assessment, Ann Arbor, Michigan, October 1976, (11 pp.).

14. Olszewski, Eugeniusz and Zacher, Lech, Political Implications and the Role of Government in the Planning Technological Future in the Socialist Countries, Anticipation (Geneva), (15), (December 1973).

15. For example, the University of Washington (Seattle) has a program in the Social Management of Technology.

16. Szczepanski, Jan, Politics and Science, Polish Perspectives 19 (2), (February 1976).

17. Szczepanski, Jan, Humanization of Technology, Polish Perspectives, 19 (5), (May 1976).

18. Lange, Oskar, Political Economy, Polish Scientific Publishers and Pergamon Press, Warsaw-London, 1963, Vol. 1.

19. Harman, Willis W., An Incomplete Guide to the Future, San Fransisco Book Co., 1976.

20. Turner, Louis, Multinational Companies and the Third World, Hill and Wang, New York, 1973.

21. Green, H. P., The Adversary Process in Technology Assessment, Technol. Soc. 5 163-167 (1970).

22. Zacher, Lech W., Technology Assessment Process in Centrally Planned Economies Second International Congress on Technology Assessment, Ann Arbor, Michigan, October 1076, (17 pp.).

23. Livingston. Dennis, International Technology Assessment and the United Nations System, Proceedings of the American Society of International Law 64, 163-171 (1970).

24. The International Institute for Applied Systems Analysis, Laxenburg, Austria, hosted a workshop on Systems Assessment of New Technology: International Perspectives, July 18-21, 1977.

25. Other UN agencies with potential interests in international technology assessment include UNIDO, UNESCO, ILO, WHO, UNDP, UNEP, and IBRD.

26. Skorov, G., Technology and Development: The Case of Developing Countries, International Aspects of Technological Innovation, UNESCO, Paris, 1971.

27. Schumacher, Erich F., Small Is Beautiful: Economics As If People Mattered, Blond \& Briggs, London, 1973

28. Tinbergen, Jan, Dolman, Antony J. and van Ettinger, Jan, Reshaping the International Order, E. P. Dutton, New York, 1976.

Received May 9, 1977 